- Original Article

\title{
Comprehensive Laboratory Analysis of Korean Acute Alcoholic Intoxication Patients Reveals the Need for a National Hepatitis B Virus Vaccination Program in Korea
}

\author{
Sang-Yong Shin* \\ Department of Laboratory Medicine, Seoul Metropolitan Dongbu Hospital, Seoul, Korea
}

Background: Acute alcoholic intoxication patients (AAIP) are a common public health problem. The aim of this study was to perform a comprehensive laboratory analysis for these patients to investigate the co-morbid medical problem.

Methods: We retrospectively reviewed laboratory findings of AAIP who were transferred to the emergency department (ED) from January 2017 to June 2017.

Results: A total of 160 male patients were enrolled. Sixteen patients $(16 / 160,10.0 \%)$ and three patients $(3 / 160,1.9 \%)$ had macrocytic anemia and microcytic anemia, respectively. A total of 33 patients $(33 / 160,20.6 \%)$ showed thrombocytopenia $\left(<150 \times 10^{9} / \mathrm{L}\right)$. Twelve patients $(12 / 159,7.5 \%)$ showed low serum albumin level $(<3.5 \mathrm{~g} / \mathrm{dL})$. Three patients $(3 / 160,1.9 \%)$ had chronic kidney disease stages $3-4$ based on estimated glomerular filtration rate. Six patients $(6 / 27,22.2 \%)$ had high hemoglobin Alc (HbAlc) level $(>7.0 \%)$. Positive rates of hepatitis B surface antigen and antiHBs antibody (anti-HBs Ab) were 3.5\% (5/141) and 49.0\% (68/141), respectively.

Conclusion: Patients with AAIP who were transferred to ED had various laboratory abnormalities (anemia, thrombocytopenia, high HbAlc). They had low positive rate of anti-HBs Ab. This might be a public health problem, suggesting the need of hepatitis B virus vaccination program for AAIP. Our data suggest the need of further nationwide studies.

Keywords: Alcoholic Intoxication; Chronic Disease; Hepatitis B Virus; Korea

Received: November 29, 2017, Revised: April 5, 2018, Accepted: April 10, 2018

*Corresponding Author: Sang-Yong Shin https://orcid.org/0000-0001-8032-1880

Tel: +82-2-920-9236, Fax: +82-2-920-9368, E-mail: hypocra@naver.com 


\section{INTRODUCTION}

Alcoholism is a common public health problem. Alcoholic consumption is relatively high in Korea (9.1 L/y per Korean adult in 2015). ${ }^{1)}$ According to the Korea National Health and Nutrition Examination Survey, the overall age-adjusted prevalence of alcohol use disorder in Korean adults was $38.8 \%$ in $2009 .^{2)}$

Our hospital has systemic healthcare service program for patients with acute alcoholic intoxication patients (AAIP). AAIP is defined as drunken status patients who were transferred our hospital by regional police officer, ambulance, homeless facilities, other hospital, etc. Mainly AAIP are homeless, found in street and transferred by regional police officer or ambulance. Our 'alcohol detoxification clinics' are consisted of medical staff (emergency medical doctors and nurses), social workers, and public health team. After medical evaluation of AAIP, some AAIP admitted to our hospital for further treatment and other AAIP may transferred to other facilities (hospital or homeless facilities, etc.).

The clinician may have difficulty to take care of AAIP due to lack of medical record or their decreased mentality/consciousness. And AAIP may have high probability of co-morbid disease. The aim of this study was to perform a comprehensive laboratory analysis for these patients to investigate the co-morbid medical problem.

\section{METHODS}

\section{Patients}

We retrospectively reviewed laboratory findings of AAIP who were transferred to Seoul Metropolitan Dongbu Hospital (an urban public hospital) from January 2017 to June 2017.

\section{Laboratory Analysis}

We analyzed the followings laboratory items: complete blood count
(CBC), hemoglobin Alc (HbAlc), C-reactive protein (CRP), albumin, total bilirubin, aspartate aminotransferase (AST), alanine aminotransferase (ALT), blood urea nitrogen (BUN), creatinine, amylase, glucose, and creatine phosphokinase (CPK). Hepatitis B surface antigen (HBs $\mathrm{Ag}$ )/anti-HBs antibody (anti-HBs Ab), hepatitis C virus antibody (anti$\mathrm{HCV} \mathrm{Ab),} \mathrm{syphilis} \mathrm{screening} \mathrm{test-rapid} \mathrm{plasma} \mathrm{regain} \mathrm{test} \mathrm{(RPR} \mathrm{test),}$ and human immunodeficiency virus antigen/antibody (HIV Ag/Ab) tests were also performed.

Chronic Kidney Disease Epidemiology Collaboration (CKD-EPI) equation and Modification of Diet in Renal Disease (MDRD) equation were used to estimate glomerular filtration rate (eGFR). ${ }^{3)}$ We investigated the prevalence of chronic kidney disease (CKD) stages 3-5 according to generally accepted criteria. ${ }^{4)}$ For CKD staging, eGFR of 45$59 \mathrm{~mL} / \mathrm{min} / 1.73 \mathrm{~m}^{2}, 30-44 \mathrm{~mL} / \mathrm{min} / 1.73 \mathrm{~m}^{2}, 15-29 \mathrm{~mL} / \mathrm{min} / 1.73 \mathrm{~m}^{2}$, and $<15 \mathrm{~mL} / \mathrm{min} / 1.73 \mathrm{~m}^{2}$ were classified as CKD stages $3 \mathrm{a}, 3 \mathrm{~b}, 4$, and 5 , respectively.

\section{Statistical Analysis}

Data are presented as mean \pm standard deviation (SD) for continuous variables (CBC, HbAlc, CRP, AST, ALT, BUN, CPK, etc.) and percentages for categorical variables (HBs Ag/anti-HBs Ab, anti-HCV Ab, RPR test, HIV Ag/Ab, and CKD stage 3-5). We presented eGFR as figure using MDRD and CKD-EPI equation. Statistical analysis was performed using IBM SPSS Statistics ver. 20.0 (IBM Corp., Armonk, NY, USA).

\section{RESULTS}

\section{Patients}

A total of 160 male patients were enrolled. Their mean age was 52.12 years (range, 32-79 years).

\section{Complete Blood Counts}

Serum CBC results are shown in Table 1. Mean \pm SD of WBC count was

Table 1. Age and serum chemistry/complete blood count results

\begin{tabular}{|c|c|c|c|c|c|}
\hline Characteristic & No. of patients & Min & $\operatorname{Max}$ & Mean \pm standard deviation & Abnormal $(\%)^{*}$ \\
\hline Age (y) & 160 & 32 & 79 & $52.12 \pm 8.57$ & - \\
\hline White blood cell $\left(\times 10^{9} / \mathrm{L}\right)$ & 160 & 2.4 & 20.9 & $7.08 \pm 2.93$ & 9.4 \\
\hline Hemoglobin (g/dL) & 160 & 6.7 & 18.9 & $13.71 \pm 2.00$ & 33.1 \\
\hline Mean cell volume (fL) & 160 & 69.6 & 116.2 & $92.06 \pm 6.36$ & 28.8 \\
\hline Platelet $\left(\times 10^{9} / \mathrm{L}\right)$ & 160 & 40 & 599 & $235.00 \pm 104.86$ & 20.6 \\
\hline Albumin (g/dL) & 159 & 2.6 & 5.2 & $4.09 \pm 0.46$ & 7.5 \\
\hline Total bilirubin (mg/dL) & 160 & 0.2 & 6.8 & $0.94 \pm 0.75$ & 12.5 \\
\hline Aspartate aminotransferase (U/L) & 160 & 15.0 & 522.0 & $92.21 \pm 91.48$ & 58.1 \\
\hline Alanine aminotransferase (U/L) & 160 & 6.0 & 178.0 & $40.41 \pm 31.47$ & 29.4 \\
\hline Blood urea nitrogen (mg/dL) & 160 & 2.0 & 51.0 & $12.01 \pm 5.90$ & 6.3 \\
\hline Creatinine (mg/dL) & 160 & 0.3 & 3.6 & $0.71 \pm 0.30$ & 1.9 \\
\hline Glucose (mg/dL) & 160 & 48.0 & 478.0 & $127.41 \pm 59.90$ & - \\
\hline Amylase (U/L) & 160 & 25.0 & 638.0 & $84.81 \pm 70.02$ & 15.6 \\
\hline Creatine phosphokinase (U/L) & 155 & 44.0 & 900.0 & $257.60 \pm 217.51$ & 22.5 \\
\hline Hemoglobin A1c (\%) & 27 & 3.7 & 10.1 & $6.22 \pm 1.12$ & 22.2 \\
\hline C-reactive protein (mg/dL) & 141 & 0.1 & 6.4 & $0.72 \pm 1.16$ & 41.8 \\
\hline
\end{tabular}

*Percentage of abnormal (exceed reference rage). 
$7.08 \pm 2.93 \times 10^{9} /$ L. Fifteen patients showed low WBC count $\left(<4.0 \times 10^{9} /\right.$ $\mathrm{L})$. Mean $\pm \mathrm{SD}$ of $\mathrm{Hb}$ was $13.71 \pm 2.00 \mathrm{~g} / \mathrm{dL}$. A total of 53 patients (33.1\%) had anemia $(<13 \mathrm{~g} / \mathrm{dL})$. Sixteen patients $(16 / 160,10.0 \%)$ had macrocytic anemia, with mean corpuscular volume (MCV) $>95 \mathrm{fL}$. Three patients $(3 / 160,1.9 \%)$ had microcytic anemia (MCV $<80 \mathrm{fL})$. A total of 33 patients $(20.6 \%)$ had thrombocytopenia $\left(<150 \times 10^{9} / \mathrm{L}\right)$.

\section{Serum Chemistry}

Serum chemistry results are summarized in Table 1. Mean AST and ALT levels were 92.21 $\pm 91.48 \mathrm{U} / \mathrm{L}$ and $40.41 \pm 31.47 \mathrm{U} / \mathrm{L}$, respectively. A total of 93 patients $(58.1 \%)$ showed elevated AST levels $(>50 \mathrm{U} / \mathrm{L})$ while 47 patients (29.4\%) showed elevated ALT levels ( $>45 \mathrm{U} / \mathrm{L}$ ). Twelve patients $(12 / 159,7.5 \%)$ showed low serum albumin levels $(<3.5 \mathrm{~g} / \mathrm{dL})$. Twelve patients (12.5\%) showed high total bilirubin levels (>1.5 mg/ dL). Six patients $(6 / 27,22.2 \%)$ showed high HbAlc levels $(>7.0 \%)$.

\section{Chronic Kidney Disease Prevalence}

Two patients had CKD stage 3a and one patient had CKD stage 4 using MDRD or CKD-EPI equation. The prevalence of CKD was 1.9\%. Distribution of eGFR is shown in Figure 1. The eGFR calculated by MDRD was higher than that calculated by CKD-EPI equation.

\section{Results of Serologic Assay for HBs Ag, Anti-HBs Ab, Anti- HCV Ab, HIV Ag/Ab, and Syphilis}

Positive rates of HBs Ag and anti-HBs Ab were 3.5\% (5/141) and 48.2\% (68/141), respectively (Tables 2, 3). Patients aged 60-69 years had the highest positive rate $(18.8 \%, 3 / 16)$ for HBs Ag. Those aged 50-59 years and those aged more than 70 years showed relatively low positive rates for anti-HBs $\mathrm{Ab}$ ( $40.0 \%$ and $25.0 \%$, respectively). Positive rates of antiHCV Ab, RPR test and HIV Ag/Ab were 2.2\% (3/139), 3.5\% (5/143), and $0 \%(0 / 142)$, respectively.

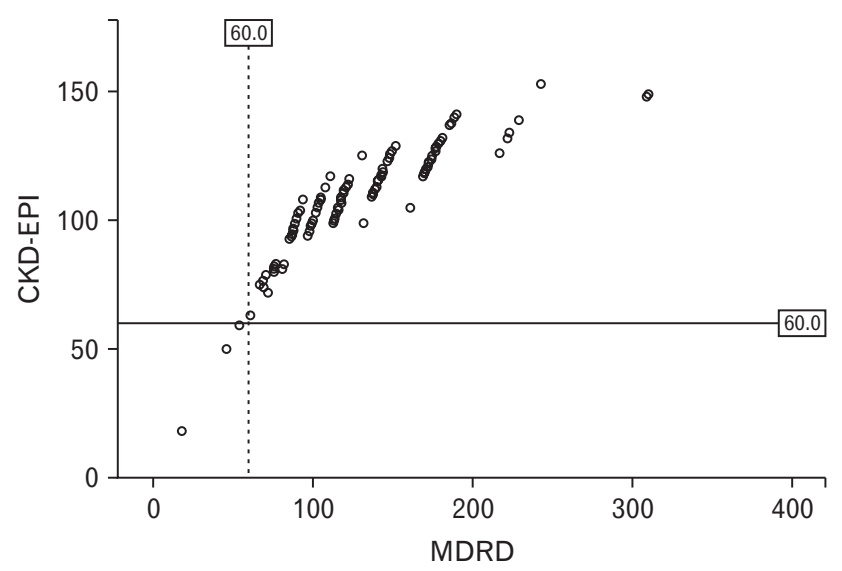

Figure 1. Estimated glomerular filtration rate calculated by MDRD and CKD-EPI equation. MDRD, Modification of Diet in Renal Disease; CKD-EPI, Chronic Kidney Disease Epidemiology Collaboration.

\section{DISCUSSION}

Although we could not access medical history of our patients, they might have a high probability of chronic diseases. Their high HbAlc levels suggest that these patients might have diabetes mellitus (DM). Elevated AST/ALT and total bilirubin but low albumin levels suggest chronic liver disease. Macrocytic anemia is commonly found in alcoholic liver disease (70.3\%) and non-alcoholic liver disease (23.3\%). ${ }^{5)}$ Maruyama et al. ${ }^{6}$ have reported that MCV is significantly correlated with estimated alcohol consumption in a study of 423 consecutive patients with various liver diseases. Fuster et al. ${ }^{7)}$ have reported that macrocytic anemia is associated with adverse mortality in patients with alcohol dependence. Thrombocytopenia has been observed in up to $76 \%$ of patients with chronic liver disease. ${ }^{8)}$ Therefore, our study population has a high probability of having DM and/or chronic liver diseases.

We found a relatively low CKD prevalence $(1.9 \%, 3 / 160$ for CKD stages 3-5 stage) in the present study. Shin et al. ${ }^{9)}$ have reported that the prevalence of CKD at stages $3-5$ is $2.6 \%-7.7 \%$ in Korean general population. Hall et al. ${ }^{10)}$ have reported that $6 \%$ of homeless people have CKD stages 3-5 in San Francisco county and city. Maziarz et al. ${ }^{11)}$ have reported that the progression rate of end stage renal diseases in homeless people is higher than that in poor but domiciled peers in San Francisco county and city. Data on CKD in Korean homeless or alcoholics are currently unavailable. Further studies are needed.

Surprisingly, we found a low seroprevalence of anti-HBs Ab (overall $48.2 \%$ ), especially in patients aged over 50 years in this study. Korea national immunization program for hepatitis B virus (HBV) and HBV perinatal transmission prevention program was introduced in 1995 and 2002, respectively. ${ }^{12)}$ Therefore, seroprevalence of HBV infection in Korea was gradually decreased. ${ }^{12)}$ Adjusted seroprevalence of HBs Ag and anti-HBs Ab in Korea 2009 (among 290,212 people undergoing

Table 2. Results of serologic assay for HBs Ag and anti-HBs Ab

\begin{tabular}{lcccrr}
\hline \multirow{2}{*}{ Age $(y)$} & \multicolumn{2}{c}{ HBs Ag } & & \multicolumn{2}{c}{ Anti-HBs Ab } \\
\cline { 2 - 3 } \cline { 5 - 6 } & Negative & Positive & & Negative & \multicolumn{1}{c}{ Positive } \\
\hline $30-39$ & $13(92.9)$ & $1(7.1)$ & & $6(42.9)$ & $8(57.1)$ \\
$40-49$ & $41(97.7)$ & $1(2.3)$ & & $18(42.9)$ & $24(57.1)$ \\
$50-59$ & $65(100.0)$ & 0 & & $39(60.0)$ & $26(40.0)$ \\
$60-69$ & $13(81.2)$ & $3(18.8)$ & & $7(43.8)$ & $9(56.2)$ \\
$\geq 70$ & $4(100.0)$ & 0 & & $3(75.0)$ & $1(25.0)$ \\
Total & $136(96.5)$ & $5(3.5)$ & & $73(51.8)$ & $68(48.2)$ \\
\hline
\end{tabular}

Values are presented as number (\%).

$\mathrm{HBs}$ Ag, hepatitis B surface antigen; anti-HBs Ab, anti-HBs antibody.

Table 3. Results of HBs Ag and anti-HBs Ab

\begin{tabular}{ccc} 
& \multicolumn{3}{c}{ Anti-HBs Ab } \\
\cline { 2 - 3 } HBs Ag & Negative & Positive \\
\hline Negative & 68 & 68 \\
Positive & 5 & 0 \\
\hline
\end{tabular}

HBs Ag, hepatitis B surface antigen; anti-HBs Ab, anti-HBs antibody. 
health check-up examinations) were $4.0 \%$ and $73.5 \%$, respectively. ${ }^{13)}$ Adjusted seroprevalence of anti-HBs Ab in male and female were $71.6 \%$ and $75.4 \%$, respectively. ${ }^{13)}$ Adjusted seroprevalence of anti-HBs $\mathrm{Ab}$ in $50-59,60-69$, and $\geq 70$ age groups were $76.5 \%, 73.5 \%$, and $69.1 \%$, respectively. ${ }^{13)}$ Seroprevalence of HBs Ag and anti-HBs Ab in homeless people in Seoul (Korea) at 1999 were $5.3 \%$ and $58.6 \%$, respectively. ${ }^{14)}$ AAIP in our study were found to be more vulnerable to HBV infection than homeless people. Our study suggests the need for vaccination program in AAIP. However, we only analyzed the small number of patients in urban region. Further nationwide studies are needed.

In general, AAIP are transferred to police office or regional hospital emergency department (ED). According to a study of Kim et al., ${ }^{15}$ AAIP might have serious acute diseases such as cardiac ischemia and cerebral hemorrhage/infarction. Therefore, police office is not suitable for care of AAIP. Regional hospital may not want to care AAIP due to financial reason or difficulty in caring for them (lack of consciousness, lack of special medical staff). These AAIP are discharged or transferred to other institutions (non-hospital) several days after receiving fundamental treatment. ${ }^{15)}$ Continuous medical service might not be available. Therefore, special program is needed to support these patients.

The limitation of our study was that a relatively small number of cases were enrolled. In addition, there was a lack of medical chart review. We only analyzed laboratory findings due to inappropriate medical records (difficulty in taking medical history).

In summary, AAIP who are transferred to ED have various laboratory abnormalities (anemia, thrombocytopenia) with high probabilities of chronic disease such as DM, CKD and chronic liver diseases. Their low positive rate of anti-HBs Ab might be of significant public healthcare concern. Our data suggest that there is a need for systemic followup and medical service program for these AAIP.

\section{CONFLICT OF INTEREST}

No potential conflict of interest relevant to this article was reported.

\section{ACKNOWLEDGMENTS}

This research was supported by a grant (NRF-2017R1D1A1B04028149) provided by the Basic Science Research Program through the National Research Foundation of Korea (NRF), funded by the Ministry of Education, Republic of Korea.

\section{REFERENCES}

1. Organization for Economic Cooperation and Development. Alcohol consumption [Internet]. Paris: Organization for Economic Cooperation and Development; 2015 [cited 2018 Jun 3]. Available from: http:// www.oecd-ilibrary.org.

2. Park SH, Kim CH, Kim DJ, Suk KT, Park HY, Lee JG, et al. Secular trends in prevalence of alcohol use disorder and its correlates in Korean adults: results from Korea National Health and Nutrition Examination Survey 2005 and 2009. Subst Abus 2012;33:327-35.

3. Levey AS, Stevens LA, Schmid CH, Zhang YL, Castro AF 3rd, Feldman $\mathrm{HI}$, et al. A new equation to estimate glomerular filtration rate. Ann Intern Med 2009;150:604-12.

4. National Kidney Foundation. K/DOQI clinical practice guidelines for chronic kidney disease: evaluation, classification, and stratification. Am J Kidney Dis 2002;39(2 Suppl 1):S1-266.

5. Morgan MY, Camilo ME, Luck W, Sherlock S, Hoffbrand AV. Macrocytosis in alcohol-related liver disease: its value for screening. Clin Lab Haematol 1981;3:35-44.

6. Maruyama S, Hirayama C, Yamamoto S, Koda M, Udagawa A, Kadowaki Y, et al. Red blood cell status in alcoholic and non-alcoholic liver disease. J Lab Clin Med 2001;138:332-7.

7. Fuster D, Sanvisens A, Bolao F, Zuluaga P, Rivas I, Tor J, et al. Markers of inflammation and mortality in a cohort of patients with alcohol dependence. Medicine (Baltimore) 2015;94:e607.

8. Afdhal N, McHutchison J, Brown R, Jacobson I, Manns M, Poordad F, et al. Thrombocytopenia associated with chronic liver disease. J Hepatol 2008;48:1000-7.

9. Shin SY, Kwon MJ, Park H, Woo HY. Comparison of chronic kidney disease prevalence examined by the chronic kidney disease epidemiology collaboration equation with that by the modification of diet in renal disease equation in Korean adult population. J Clin Lab Anal 2014;28:320-7.

10. Hall YN, Choi AI, Himmelfarb J, Chertow GM, Bindman AB. Homelessness and CKD: a cohort study. Clin J Am Soc Nephrol 2012;7:1094102.

11. Maziarz M, Chertow GM, Himmelfarb J, Hall YN. Homelessness and risk of end-stage renal disease. J Health Care Poor Underserved 2014;25:1231-44.

12. Cho EJ, Kim SE, Suk KT, An J, Jeong SW, Chung WJ, et al. Current status and strategies for hepatitis B control in Korea. Clin Mol Hepatol 2017;23:205-11.

13. Lee BS, Cho YK, Jeong SH, Lee JH, Lee D, Park NH, et al. Nationwide seroepidemiology of hepatitis B virus infection in South Korea in 2009 emphasizes the coexistence of HBsAg and anti-HBs. J Med Virol 2013;85:1327-33.

14. Song HJ, Cho CH, Kang JH, Hwang WS, Han HK. Health status and behavior of homeless in Seoul. J Korean Acad Fam Med 2000;21:357-66.

15. Kim DH, You EY, Jung SK, Rhee JE, Suh GJ, Youn YK. The clinical analysis of the homeless visiting emergency medical centers. J Korean Soc Emerg Med 2002;13:294-9. 